\title{
Effect of a small dose of aspirin on quantitative test of 24-h urinary protein in patients with hypertension in pregnancy
}

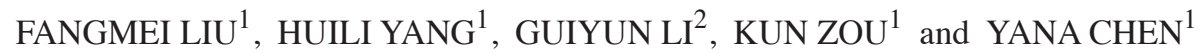 \\ ${ }^{1}$ Department of Obstetrics and Gynecology, Jinan Central Hospital, Shandong University, Jinan, Shandong 250013; \\ ${ }^{2}$ Department of Obstetrics and Gynecology, The First People's Hospital of Jinan, Jinan, Shandong 250000, P.R. China
}

Received January 25, 2016; Accepted August 19, 2016

DOI: 10.3892/etm.2016.3924

\begin{abstract}
The aim of the present study was to determine the effect of a small dose of aspirin on a quantitative test of 24-h urinary protein in patients with hypertension in pregnancy. In total, 224 patients with hypertension in pregnancy were continuously selected and were randomly divided into the control group (50 cases with conventional therapy), aspirin $50 \mathrm{mg}$ /day group (60 cases), aspirin $75 \mathrm{mg}$ /day group (58 cases), and aspirin $100 \mathrm{mg} /$ day group (56 cases). Clinical effects were compared from 16 gestational weeks to childbirth. According to the comparison in the four groups, there was no statistical difference in the mean arterial pressure, pre-eclampsia rate, gestational weeks, and caesarean section rate $(\mathrm{p}>0.05)$. The 24-h urinary protein and endothelin-1 (ET-1) level were significantly decreased following treatment, and were less than the control and $50 \mathrm{mg} / \mathrm{day}$ groups. The superoxide dismutase (SOD) level was significantly increased, and higher than the control and $50 \mathrm{mg} /$ day groups. In terms of the 75 and $100 \mathrm{mg} /$ day, control and $50 \mathrm{mg} /$ day groups, there was no statistical difference $(\mathrm{p}>0.05)$. A comparison of the complication rate in the four groups of fetuses during the perinatal period, no statistical difference was observed $(\mathrm{p}>0.05)$. Thus, the results show that, regarding patients with hypertension in pregnancy, $75 \mathrm{mg}$ /day aspirin can decrease the 24-h urinary protein, SOD, and ET-1 level. However, the results remain to be confirmed to improve maternal and infant outcome in delivery.
\end{abstract}

\section{Introduction}

Hypertension in pregnancy is a common disease that exhibits clinical characteristics including hypertension, edema, albuminuria, twitch, coma, heart and renal failure, and even maternal-fetal death (?). The 2013 guidelines for hypertension

Correspondence to: Dr Yana Chen, Department of Obstetrics and Gynecology, Jinan Central Hospital, Shandong University, 44 Wenhua Xi Road, Jinan, Shandong 250013, P.R. China

E-mail: mifdpmx51081@163.com

Key words: aspirin, hypertension in pregnancy, 24-h urinary protein, superoxide dismutase, endothelin-1 in pregnancy released by ACOG recommends that it is essential to have a quantitative test of 24-h urinary protein and diagnosis of pre-eclampsia (1). Additionally, with biochemical indices such as superoxide dismutase (SOD) and endothelin-1 (ET-1), the accuracy of diagnosis may be highly improved in the early stage of pre-eclampsia.

For patients at high risk of suffering from pre-eclampsia a small dose of aspirin (60-80 mg/day) is considered safe and effective. Although recording of the starting time and administration of aspirin to patients with hypertension in pregnancy is a recent phenomenon in China, previous findings have shown that aspirin ( $50 \mathrm{mg} /$ day) is definitely beneficial to reduce the incidence of pre-eclampsia and intracranial hemorrhage of fetus (2). In addition, aspirin at a dose of $100 \mathrm{mg} /$ day may be more beneficial than $50 \mathrm{mg}$ /day without increasing complications during the perinatal period (3).

The present randomized, double-blind and clinical control study was performed to determine whether a small dose of aspirin is useful to patients with hypertension in pregnancy.

\section{Patients and methods}

A total of 224 patients with hypertension in pregnancy were successively selected from October, 2012 to October, 2015, at the Jinan Central Hospital (Shandong, China). The inclusion criteria for the study were: i) $\geq 18$ but $<50$ years of age; ii) in accordance with 2013 standards for hypertension in pregnancy issued by ACOG, but with high risk of pre-eclampsia such as $>40$ years, obesity, chronic hypertension, chronic kidney disease, type 1 or 2 diabetes mellitus, family history of pre-eclampsia, previous pregnancy along with pre-eclampsia, thrombosis history, and systemic lupus erythematosus; iii) single birth; and iv) no past history of having aspirin and anticoagulant medications such as warfarin, and no complications such as rheumatic disease and chronic atrial fibrillation that require ingesting aspirin or warfarin. The exclusion criteria were: i) artificial insemination; ii) coagulation disorders; iii) hard to control medication for hypertension in pregnancy; iv) an allergy to aspirin; and v) bad compliance.

The present study was approved by the ethics committee of the Jinan Central Hospital. Written informed consent was obtained from the patients. According to the order of hospitalization, patients were randomly divided into the control group 
(50 cases with conventional therapy), aspirin $50 \mathrm{mg} /$ day group (60 cases), aspirin $70 \mathrm{mg} / \mathrm{day}$ group (58 cases), and aspirin $100 \mathrm{mg} / \mathrm{d}$ group (56 cases). In the control group, patients were 22-35 years of age, with an average of $26.7 \pm 5.5$ years. The gestational weeks were 10-15 weeks, with an average of $14.7 \pm 3.2$ weeks. BMI was $25.5-35.7 \mathrm{~kg} / \mathrm{m}^{2}$, with an average of $32.6 \pm 7.5 \mathrm{~kg} / \mathrm{m}^{2}$. Concerning the $50 \mathrm{mg} /$ day group, patients were 23-36 years, with an average of $27.2 \pm 5.8$ years. The gestational weeks were 11-16 weeks, with an average of $15 \pm 3.6$ weeks. BMI was $25.3-36.2 \mathrm{~kg} / \mathrm{m}^{2}$, with an average of $34.1 \pm 7.7 \mathrm{~kg} /$ $\mathrm{m}^{2}$. In the $75 \mathrm{mg} /$ day group, patients were $24-33$ years, with an average of $26.5 \pm 5.3$ years. The gestational weeks were $12-15.5$ weeks, with an average of $13.8 \pm 3.9$ weeks. BMI was $23.8-35.9 \mathrm{~kg} / \mathrm{m}^{2}$, with an average of $32.7 \pm 5.9 \mathrm{~kg} / \mathrm{m}^{2}$. In the $100 \mathrm{mg}$ /day group, patients were 23-34 years, with an average of 25.5 \pm 4.6 years. The gestational weeks were 9-15.6 weeks, with an average of $14.4 \pm 5.2$ weeks. BMI was $23.5-34.7 \mathrm{~kg} / \mathrm{m}^{2}$, with an average of $31.8 \pm 6.9 \mathrm{~kg} / \mathrm{m}^{2}$. A comparison of the four groups with regard to age, gestational weeks and BMI, yielded no statistical significant difference ( $p>0.05)$.

Treatment therapy. On the basis of the guideline, conventional therapy included moderate training. Calcium was recommended if there was a lack of the basic volume thereof. Patients with mild hypertension in pregnancy (continuous blood pressure $<160 / 110 \mathrm{mmHg}$ ) or pre-eclampsia were not recommended to have a hypotensor. If patients suffered from pre-eclampsia with severe hypertension in pregnancy (continuous blood pressure $\geq 160 / 110 \mathrm{mmHg}$ ), anti-hypertensive treatment was considered a good choice. For example, patients were initially administered anti-hypertensive drugs orally, followed by intravenous injection. Magnesium sulfate was also administered in combination if required. However, vitamin $\mathrm{C}$ and $\mathrm{E}$ without salt restriction were not recommended. Termination of pregnancy had to be performed in time, and the manner of delivery was required to be in accordance with gestational weeks, fetal presentation, cervical ripeness and maternal-fetal situation. Anti-hypertensive treatment was performed when continuous hypertension was $\geq 150 / 100 \mathrm{mmHg}$ after delivery. If hypertension was $\geq 160 / 110 \mathrm{mmHg}$, patients were required to undergo treatment within an hour.

From 16 gestational weeks to childbirth, aspirin from Bayer (Berlin, Germany) (100 mg/tablet, 30 tablets in all) was taken before bedtime. In addition, blood routine and blood coagulation were monitored regularly (once per month) in case of abnormal reaction. Patients accepted drug withdrawal immediately when abnormal reaction occurred.

Observation index. Patients were divided into four groups to determine differences in MAP, pre-eclampsia incidence, gestational weeks and the caesarean section rate, test of 24-h urinary protein, SOD and ET-1, and complications during the perinatal period. For SOD and ET-1 peripheral blood of $5 \mathrm{ml}$ was collected on an empty stomach. The upper stratum was removed by centrifugation at 2,800 $\mathrm{x}$ g after $30 \mathrm{~min}$, and kept at $4^{\circ} \mathrm{C}$ for the test. For SOD the xanthine oxidase method was used, whereas radioimmunoassay was used for ET-1. Kits were purchased from R\&D Systems, Inc. (Minneapolis, MN, USA), and the manufacturer's instructions were strictly followed.
Statistical analysis. SPSS 20.0 software (Chicago, IL, USA) was used for the statistical analysis. Measurement data were presented as mean \pm standard deviation. ANOVA analysis was used for comparison between groups with with preset $\alpha<0.05$ for significance. For comparison between two groups, the LSD and Bonferroni tests were used to determine any significant difference $(1 / 4 \alpha<0.013)$. For comparisons before and after the treatment, the paired-sample t-test was used. Enumeration data were presented as percentage and the $\chi^{2}$ test was used for data analysis. There was statistical difference when $\mathrm{p}<0.05$.

\section{Results}

Comparison of MAP, pre-eclampsia rate, gestational weeks and caesarean section. No statistical difference for MAP, pre-eclampsia, gestational weeks and caesarean section was observed following a comparison in the four groups ( $p>0.05)$ (Table I).

Comparison of 24-h urinary protein, SOD and ET-1. A comparison of the 24-h urinary protein, SOD and ET-1 indicated no statistical difference before treatment $(p>0.05)$. After treatment, the 24-h urinary protein and ET-1 was decreased significantly, lower than the control and $50 \mathrm{mg} /$ day groups. By contrast, SOD was increased, and was higher than the control and $50 \mathrm{mg} / \mathrm{day}$ groups. These results were statistically different $(\mathrm{p}<0.05)$. No statistical difference following for the 75 and $100 \mathrm{mg} /$ day, control and $50 \mathrm{mg} /$ day groups $(\mathrm{p}>0.05)$ was found (Table II).

Comparison in complications during the perinatal period. No statistical difference following a comparison of complications during the perinatal period of the four groups was found (Table III).

\section{Discussion}

Previous findings have shown that using aspirin early is beneficial for pregnant women with high risk of pre-eclampsia (4). However, this is not the case for patients at low risk. Additionally, a small dose of aspirin does not lead to bleeding and placental abruption, and is considered the first choice of treatment to prevent the problem in pregnant women who are at high risk of pre-eclampsia (4). Nevertheless, there is currently no concensus on the appropriate dose of aspirin to be used. The 2010 guidelines for hypertension in pregnancy released by NICE suggested that it was safe and effective for women with pre-eclampsia at middle and high risk should take $75 \mathrm{mg}$ of aspirin daily from 12 gestational weeks to childbirth (5). Previous findings have shown no statistical differences between the incidence of bleeding before and after delivery with aspirin (6). On the basis of different doses of aspirin in clinical treatment, it has been concluded that taking $>150 \mathrm{mg}$ of aspirin per day may lead to a high incidence of bleeding after delivery (7). Thus, a small dose of aspirin may affect the prevention of pre-eclampsia without increasing the risk of bleeding in mother and infant.

Oxidative stress is associated with the mechanism of pre-eclampsia (8). Antioxidants such as vitamin C and E may be useful in the prevention of pre-eclampsia. Taking vitamin C 
Table I. Comparison of MAP, pre-eclampsia rate, gestational weeks and caesarean section.

\begin{tabular}{lcccccc}
\hline Groups & Cases & Before MAP (mmHg) & After MAP & Pre-eclampsia & Gestational week (weeks) & Caesarean section \\
\hline Control & 50 & $115.8 \pm 15.9$ & $88.2 \pm 13.2$ & $16(32.0)$ & $35.6 \pm 3.3$ & $6(12.0)$ \\
$50 \mathrm{mg} /$ day & 60 & $117.6 \pm 16.7$ & $86.4 \pm 14.6$ & $22(36.7)$ & $36.4 \pm 3.5$ & $7(11.7)$ \\
$75 \mathrm{mg} /$ day & 58 & $114.4 \pm 18.2$ & $85.8 \pm 12.7$ & $20(34.5)$ & $36.2 \pm 3.6$ & $8(13.8)$ \\
$100 \mathrm{mg}$ /day & 56 & $109.2 \pm 20.2$ & $86.6 \pm 16.9$ & $21(37.5)$ & $35.8 \pm 3.7$ & 0.836 \\
F & & 0.526 & 0.637 & 0.423 & 0.725 & 0.138 \\
P-value & 0.325 & 0.421 & 0.935 & & 0.987 \\
\hline
\end{tabular}

Table II. Comparison of 24-h urinary protein, SOD and ET-1.

\begin{tabular}{|c|c|c|c|c|c|c|c|c|c|c|c|c|}
\hline \multirow[b]{2}{*}{ Groups } & \multicolumn{4}{|c|}{ 24-h urinary protein $(\mathrm{g})$} & \multicolumn{4}{|c|}{$\mathrm{SOD}(\mathrm{nU} / \mathrm{ml})$} & \multicolumn{4}{|c|}{ ET-1 (ng/l) } \\
\hline & Before & After & $\mathrm{t}$ & P-value & Before & After & $\mathrm{t}$ & P-value & Before & After & $\mathrm{t}$ & P-value \\
\hline Control & $2.3 \pm 0.9$ & $1.8 \pm 0.5$ & 1.201 & 0.967 & $46.7 \pm 13.5$ & $53.4 \pm 15.2$ & 0.637 & 0.432 & $86.5 \pm 20.1$ & $83.4 \pm 26.9$ & 0.467 & 0.102 \\
\hline $50 \mathrm{mg} /$ day & $2.4 \pm 0.8$ & $1.6 \pm 0.7$ & 1.367 & 0.768 & $48.2 \pm 14.9$ & $55.9 \pm 16.9$ & 0.938 & 0.558 & $85.2 \pm 23.5$ & $81.6 \pm 23.5$ & 0.539 & 0.325 \\
\hline $75 \mathrm{mg} /$ day & $2.5 \pm 0.7$ & $0.9 \pm 0.4$ & 4.938 & 0.039 & $46.9 \pm 16.3$ & $127.4 \pm 34.5$ & 5.634 & 0.035 & $88.4 \pm 24.6$ & $48.5 \pm 14.7$ & 6.324 & 0.028 \\
\hline $100 \mathrm{mg} /$ day & $2.3 \pm 0.8$ & $1.1 \pm 0.6$ & 5.022 & 0.037 & $47.5 \pm 18.5$ & $113.8 \pm 33.6$ & 5.705 & 0.033 & $87.5 \pm 28.7$ & $46.3 \pm 16.9$ & 6.532 & 0.023 \\
\hline $\mathrm{F}$ & 0.635 & 5.624 & & & 0.837 & 5.768 & & & 0.584 & 6.967 & & \\
\hline P-value & 0.427 & 0.033 & & & 0.639 & 0.031 & & & 0.323 & 0.015 & & \\
\hline
\end{tabular}

SOD, superoxide dismutase; ET-1, endothelin-1.

Table III. Comparison of complications during the perinatal period (cases \%).

\begin{tabular}{|c|c|c|c|c|c|c|}
\hline Groups & Cases & $\begin{array}{c}\text { Intracranial and ventricular } \\
\text { hemorrhage }\end{array}$ & Ischemia, hypoxia & Placental abruption & Death & Complication rate \\
\hline Control & 50 & 0 & 2 & 1 & 1 & $4(8.0)$ \\
\hline $50 \mathrm{mg} /$ day & 60 & 1 & 3 & 0 & 1 & $5(8.3)$ \\
\hline $75 \mathrm{mg} /$ day & 58 & 2 & 3 & 0 & 1 & $6(10.3)$ \\
\hline $100 \mathrm{mg} /$ day & 56 & 2 & 1 & 1 & 1 & $5(8.9)$ \\
\hline$\chi^{2}$ & & & & & & 0.218 \\
\hline $\mathrm{P}$-value & & & & & & 0.975 \\
\hline
\end{tabular}

and $\mathrm{E}$ through lots of random tests and case-control study on placebo has been shown not to be useful (9). Urinary protein is a sign of early hypertensive kidney lesion and of disease progression as in the case of pre-eclampsia (10). Different levels of urinary protein are positively correlated with the degree of blood pressure (11). An increase of urinary protein may lead to the ultrastructure of the local spherule-tubule cell in kidney to change, and the electrical load to be raised. Furthermore, urinary protein may leak out under such poor circulation. Additionally, there is disorder in the local part of the kidney, whole oxygen-free radical metabolism, and vascular endothelial cell (12). Active metabolism in placenta, higher oxygen consumption, more oxygen-free radicals, and a balance of oxidation and anti-oxidation are major factors in the prevention of pre-eclampsia (13). SOD is a free radical scavenger that lies in the cells of aerobic metabolism. It plays a role in controlling the balance of creating and removing free radicals (14). Previous findings have shown that a certain dose of aspirin (75 and $100 \mathrm{mg}$ ) may raise the SOD level, relieve oxidation reactions and improve metabolism in urinary protein (15).

Owing to feeding cells, the placenta is likely to undergo hypoxia and ischemia and then release a variety of inflammatory factors including ET-1 with vasoconstriction. In addition, with the damage in vascular endothelial cells, internal and external coagulation mechanism may function. Thus, platelet aggregation is associated with thrombus formation (16). ET-1 lies in endothelial cells, which is the most vasoactive substance. It increases obviously during the middle and late pregnancy of normal pregnant women, but also increases in women with hypertension. There is a close relationship with pre-eclampsia in incidence and severity (17). Aspirin is important in retarding platelet aggregation and thrombus formation by inhibiting the activity of epoxidase, interfering arachidonic 
acid to TXA2 and increasing PG12 (18). Thus, a certain dose of aspirin (75 and $100 \mathrm{mg}$ ) plays an important role in reducing ET-1 and improving metabolism in urinary protein.

The present findings suggest that there was no statistical significance with regard to MAP, pre-eclampsia, gestational weeks and the caesarean section rate in the four groups studied. Although a certain dose of aspirin can reduce urinary protein, SOD and ET-1, whether it can change the clinical outcome is not clear. Different from the previous studies, which identifed a small dose of aspirin as being capable of preventing middle and high risk pre-eclampsia, different races and samples were also taken into account in the current study. No statistical significance in the incidence of complications during the perinatal period was observed. Thus, no association between the two factors may exist.

In conclusion, $75 \mathrm{mg}$ of aspirin daily can reduce 24-h urinary protein, SOD, and ET-1 in those patients with hypertension in pregnancy. Nevertheless, more studies are required to determine whether it can improve delivery outcome of mother and infant.

\section{References}

1. American College of Obstetricians and Gynecologists; Task Force on Hypertension in Pregnancy: Hypertension in pregnancy. Report of the American College of Obstetricians and Gynecologists Task Force on Hypertension in Pregnancy. Obstet Gynecol 122: 1122-1131, 2013.

2. Duley L, Henderson-Smart DJ, Meher S and King JF: Antiplatelet agents for preventing pre-eclampsia and its complications Cochrane Database Syst Rev 18: CD004659, 2007.

3. Bujold E, Roberge S, Lacasse Y, Bureau M, Audibert F, Marcoux S, Forest JC and Giguère Y: Prevention of preeclampsia and intrauterine growth restriction with aspirin started in early pregnancy: A meta-analysis. Obstet Gynecol 116: 402-414, 2010.

4. Rossi AC and Mullin PM: Prevention of pre-eclampsia with low-dose aspirin or vitamins $\mathrm{C}$ and $\mathrm{E}$ in women at high or low risk: a systematic review with meta-analysis. Eur J Obstet Gynecol Reprod Biol 158: 9-16, 2011.

5. Redman CW: Hypertension in pregnancy: the NICE guidelines. Heart 97: 1967-1969, 2011.
6. Avala DE, Ucieda R and Hermida RC: Chronotherapy with low-dose aspirin for prevention of complications in pregnancy. Chronobiol Int 9: 1-20, 2012.

7. Askie LM, Duley L, Henderson-Smart DJ and Stewart LA; PARIS Collaborative Group: Antiplatelet agents for prevention of pre-eclampsia: a meta-analysis of individual patient data. Lancet 369: 1791-1798, 2007.

8. Ramma W and Ahmed A: Is inflammation the cause of pre-eclampsia? Biochem Soc Trans 39: 1619-1627, 2011.

9. Bodnar LM, Catov JM, Simhan HN, Holick MF, Powers RW and Roberts JM: Maternal vitamin D deficiency increases the risk of preeclampsia. J Clin Endocrinol Metab 92: 3517-3522, 2007.

10. Thornton CE, Makris A, Ogle RF, Tooher JM and Hennessy A: Role of proteinuria in defining pre-eclampsia: clinical outcomes for women and babies. Clin Exp Pharmacol Physiol 37: 466-470, 2010.

11. Chan P, Brown M, Simpson JM and Davis G: Proteinuria in pre-eclampsia: how much matters? BJOG 112: 280-285, 2005.

12. Newman MG, Robichaux AG, Stedman CM, Jaekle RK, Fontenot MT, Dotson T and Lewis DF: Perinatal outcomes in preeclampsia that is complicated by massive proteinuria. Am J Obstet Gynecol 188: 264-268, 2003.

13. Spinnato JA II, Freire S, Pinto E Silva JL, Cunha Rudge MV, Martins-Costa S, Koch MA, Goco N, Santos CB, Cecatti JG, Costa R, et al: Antioxidant therapy to prevent preeclampsia: a randomized controlled trial. Obstet Gynecol 110: 1311-1318, 2007.

14. Garcia-Benavides L, Guzman-Sanchez A, Hernandez-Mora FJ, Muro-Gomez AM, Gomez-Martinez ML and Siller-Lopez FR: PP078. Total antioxidant capacity in patients with pregnancy induced hypertension: its relation to maternal and/or perinatal complications. Pregnancy Hypertens 2: 282-283, 2012.

15. Abdolvahabi A, Shi Y, Rhodes NR, Cook NP, Marti AA and Shaw BF: Arresting amyloid with coulomb's law: Acetylation of ALS-linked SOD1 by aspirin impedes aggregation. Biophys J 108: 1199-1212, 2015.

16. Bujold E: Prevention of pre-eclampsia with low-dose aspirin. J Postgrad Med 57: 89-90, 2011.

17. Jain A: Endothelin-1: a key pathological factor in pre-eclampsia? Reprod Biomed Online 25: 443-449, 2012.

18. Moore GS, Allshouse AA, Winn VD, Galan HL and Heyborne KD: Baseline placental growth factor levels for the prediction of benefit from early aspirin prophylaxis for preeclampsia prevention. Pregnancy Hypertens 5: 280-286, 2015. 